\title{
Stenotrophomonas, Achromobacter, and Nonmelioid Burkholderia Species: Antimicrobial Resistance and Therapeutic Strategies
}

\author{
${ }^{1}$ Victorian Infectious Diseases Reference Laboratory, Peter Doherty \\ Institute, Victoria, Australia \\ 2 Department of Infectious Diseases, The Alfred Hospital, Victoria, \\ Australia \\ ${ }^{3}$ Department of Microbiology, Monash University, Clayton, Victoria, \\ Australia
}

lain J. Abbott, MBBS ${ }^{1}$ Anton Y. Peleg, MBBS, PhD, MPH, FRACP2,3

\author{
Address for correspondence lain J. Abbott, MBBS, Victorian Infectious \\ Diseases Reference Laboratory, Doherty Institute, 792 Elizabeth \\ Street, Melbourne, Victoria, Australia 3000 \\ (e-mail: iainabbott@gmail.com).
}

Semin Respir Crit Care Med 2015;36:99-110.

\begin{abstract}
Keywords

- antimicrobial resistance

- nonfermenting Gram-negative bacteria

- biofilm

- cystic fibrosis

- immunocompromised patient

- intensive care unit

- antimicrobial susceptibility testing

Stenotrophomonas maltophilia, Achromobacter xylosoxidans, and nonmelioid Burkholderia species, namely, Burkholderia cepacia complex, collectively are a group of troublesome nonfermenters. Although not inherently virulent organisms, these environmental Gram negatives can complicate treatment in those who are immunocompromised, critically ill in the intensive care unit and those patients with suppurative lung disease, such as cystic fibrosis. Through a range of intrinsic antimicrobial resistance mechanisms, virulence factors, and the ability to survive in biofilms, these opportunistic pathogens are well suited to persist, both in the environment and the host. Treatment recommendations are hindered by the difficulties in laboratory identification, the lack of reproducibility of antimicrobial susceptibility testing, the lack of clinical breakpoints, and the absence of clinical outcome data. Despite trimethoprim-sulfamethoxazole often being the mainstay of treatment, resistance is widely encountered, and alternative regimens, including combination therapy, are often used. This review will highlight the important aspects and unique challenges that these three nonfermenters pose, and, in the absence of clinical outcome data, our therapeutic recommendations will be based on reported antimicrobial susceptibility and pharmacokinetic/pharmacodynamic profiles.
\end{abstract}

Nonfermenting Gram-negative bacteria (GNB) are typified by Pseudomonas and Acinetobacter species, which are widely distributed in natural environments, including soil, water, rhizosphere, and agriculture. Less is known about other nonfermenters, such as Stenotrophomonas maltophilia, Burkholderia cepacia complex, and Achromobacter xylosoxidans, which largely share the same environmental niche and are increasingly being recognized as emerging pathogens in hospitalized, immunocompromised, and cystic fibrosis (CF) patients.

\section{Classification and Taxonomy}

The taxonomy of this group of organisms continues to change as more information is gathered (see - Fig. 1). S. maltophilia was originally classified within the genus Pseudomonas, but it was reassigned to the Gammaproteobacteria class, initially within the genus Xanthomonas, and subsequently moved to Stenotrophomonas with seven other named species. Genomic subtyping among S. maltophilia isolates demonstrates remarkable diversity suggesting that
DOI http://dx.doi.org/ 10.1055/s-0034-1396929. ISSN 1069-3424. 


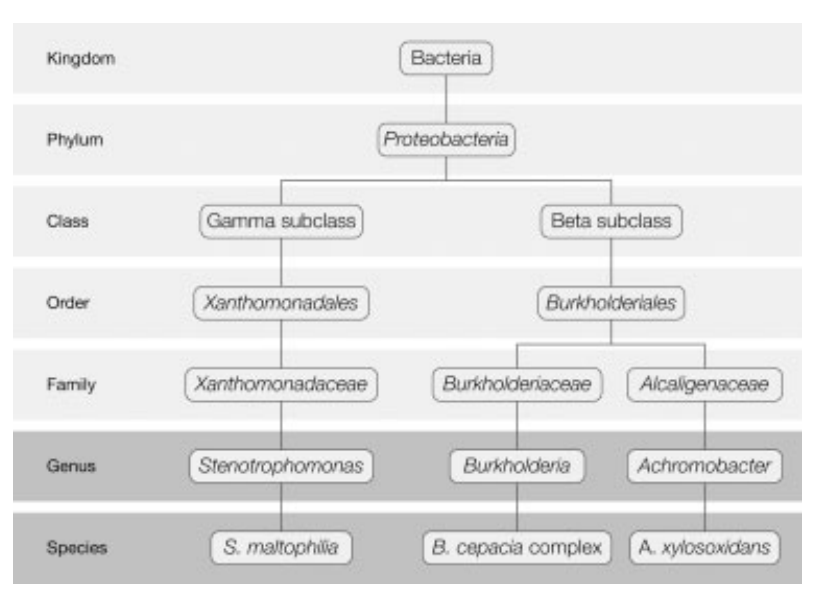

Fig. 1 Taxonomy of Stenotrophomonas maltophilia, Burkholderia cepacia complex, and Achromobacter xylosoxidans.

S. maltophilia may represent a "complex" of species. ${ }^{1,2}$ The Burkholderia genus, also originally of the genus Pseudomonas, contains more than 60 species and is found within the Betaproteobacteria class and Burkholderiales order. B. cepacia is referred to as a "complex" as it contains at least 17 genetically related species, formally designated as numbered genomovars (see - Table 1) ${ }^{3}$ B. multivorans (genomovar II) and $B$. cenocepacia (genomovar III) are the most commonly identified and clinically relevant species within the complex. B. cenocepacia is further split into four phylogenetic lineages (IIIA, IIIB, IIIC, and IIID) based on the polymorphism of the recA gene. ${ }^{4,5}$ In $\mathrm{CF}$, patients colonized with $B$. cenocepacia, especially lineage IIIA, have a higher mortality following lung transplantation. ${ }^{6-9}$ A. xylosoxidans is similarly classified within the Burkholderiales order, but within the Alcaligenaceae family. Although previously assigned to the Alcaligenes genus, A. xylosoxidans now remains the type species within the Achromobacter genus, together with six other named species and multiple genogroups. ${ }^{10-12}$

\section{Epidemiology, Transmission, and Clinical Significance}

Stenotrophomonas, Burkholderia, and Achromobacter species are all ubiquitous environmental organisms found in water, soil, the rhizosphere, and in and on plants. They have a worldwide distribution. SENTRY data from 1997 to 2003 identified 221,084 bacterial isolates, including $11.5 \%$ that were nonenteric GNB, of which Pseudomonas and Acinetobacter species accounted for the majority (82.7\%). ${ }^{13}$ of the remaining nonenteric GNB isolated, 3,509 isolates were analyzed, of which S. maltophilia accounted for $59.2 \%$, B. cepacia complex 7.7\%, and Achromobacter species 6.7\%. ${ }^{13}$ Amongst cancer patients at the MD Anderson Cancer Centre, ${ }^{14}$ the incidence of $S$. maltophilia had increased over time, accounting for the 5th most common Gram-negative bacterial isolate. In tropical Australia, bacteremia cases from 2000 to 2010 (over 4,500 cases), S. maltophilia accounted for $1.6 \%$ of cases; Achromobacter species $0.2 \%$; and B. cepacia complex was not identified. $^{15}$
The proportion of CF patients colonized with traditional pathogens has largely remained stable over time, with P. aeruginosa isolated in 60 to $80 \%$ of patients, and methicillin-sensitive Staphylococcus aureus in 30 to $60 \%$, while the prevalence of $B$. cepacia complex remains low (3-5\%) with a declining incidence. ${ }^{16,17}$ There is, however, an increasing prevalence of S. maltophilia (4-15\%), A. xylosoxidans (3-8\%), nontuberculous mycobacteria (5-13\%), and methicillinresistant $S$. aureus $(17.2 \%) .{ }^{16,17}$ In a French regional CF center, over 5,000 sputa were collected from 300 CF patients. The incidence of Pseudomonas was 59\%, S. maltophilia $18.9 \%$, B. cenocepacia $13.8 \%$, and A. xylosoxidans $6.9 \%$. Coinfection with two or more of these pathogens was noted to be common. ${ }^{10}$ In a multicenter study from Australia and New Zealand, CF patients colonized with $B$. cepacia complex were investigated. The authors identified B. multivorans in $29.3 \%$ and $B$. cenocepacia in $45.7 \%$, with some geographic variability. ${ }^{18}$ Some CF centers in Australia are dominated instead by $B$. multivorans (A.Y. Peleg, written personal communication, July 2014). Multilocus sequence typing scheme has demonstrated that several different Achromobacter species and genogroups can infect patients with $\mathrm{CF}$, although less is known about the possible differences in tropism and pathogenicity between the different species. ${ }^{11,12,19}$

Person-to-person transmission of these multidrug-resistant pathogens, especially among $\mathrm{CF}$ patients, remains a concern. Unlike B. cepacia complex, where evidence for cross-transmission is well reported, ${ }^{20}$ less is known for $S$. maltophilia and $A$. xylosoxidans. However, case reports have documented incidences of patient cross-transmission. ${ }^{10,21,22}$

All three organisms are capable of causing a variety of infections, including bacteremia, pneumonia, meningitis, urinary tract infections, and nosocomial infections from contaminated environmental sources (e.g., medications, nebulizers, dialysis fluids, saline solution, disinfectants, and contact lens fluid) have been reported. A major virulence factor of these organisms is their ability to produce and survive within biofilms. ${ }^{23-27}$ Biofilm production is associated with resistance to environmental factors by promoting intimate attachment to surfaces, resistance to phagocytic activity and other host immune factors, shielding from antimicrobial activity and enhanced spread across surfaces via bacterial motility. In polymicrobial infections, interspecies interactions have been demonstrated such that different species within the same biofilm can respond to each other's signaling systems and provide survival advantages to the entire polymicrobial community. ${ }^{28-30}$

\section{Beyond Human Pathogens}

B. cepacia complex, S. maltophilia, and A. xylosoxidans share many beneficial environmental effects (see - Fig. 2), although B. cepacia complex is recognized as a pathogen of onions. These organisms produce antimicrobial compounds that protect plants, cause disease in nematodes, and generate factors that promote plant growth. They also have the ability to degrade a wide variety of compounds, including pollutants and heavy metals, enabling these organisms to be effective 
Table 1 Burkholderia cepacia complex species ${ }^{\mathrm{a}}$

\begin{tabular}{|c|c|c|}
\hline Species & Former designation & Reported sources \\
\hline B. серасіа & Genomovar I & $\begin{array}{l}\text { Infections in CF and non-CF patients }{ }^{\mathrm{b}} \\
\text { Environment: soil, rhizosphere, plant, and river water } \\
\text { Bioremediation and biocontrol agent }\end{array}$ \\
\hline B. multivorans & Genomovar II & $\begin{array}{l}\text { Infections in CF and non-CF patients } \\
\text { Environment: soil, rhizosphere, plant, river water, and contaminant }\end{array}$ \\
\hline B. cenocepacia & $\begin{array}{l}\text { Genomovar III } \\
\text { (four lineages, A-D) }\end{array}$ & $\begin{array}{l}\text { Infections in CF and non-CF patients } \\
\text { Environment: soil, rhizosphere, plant, river water, and industrial } \\
\text { contaminant } \\
\text { Biocontrol agent }\end{array}$ \\
\hline B. stabiliz & Genomovar IV & $\begin{array}{l}\text { Infections in CF and non-CF patients } \\
\text { Environment: plant, hospital contaminant }\end{array}$ \\
\hline B. vietnamiensis & Genomovar V & $\begin{array}{l}\text { Infections in CF and non-CF patients } \\
\text { Environment: soil, rhizosphere, plant, river water, and industrial } \\
\text { contaminant } \\
\text { Bioremediation and biocontrol agent }\end{array}$ \\
\hline B. dolosa & Genomovar VI & $\begin{array}{l}\text { Infections in CF patients only } \\
\text { Environment: rhizosphere, plant }\end{array}$ \\
\hline B. ambifaria & Genomovar VII & $\begin{array}{l}\text { Infections in CF and non-CF patients } \\
\text { Environment: soil, rhizosphere } \\
\text { Biocontrol agent }\end{array}$ \\
\hline B. anthina & Genomovar VIII & $\begin{array}{l}\text { Infections in CF, non-CF patients and turtles } \\
\text { Environment: soil, rhizosphere, river water, and hospital contaminant }\end{array}$ \\
\hline B. pyrrocinia & Genomovar IX & $\begin{array}{l}\text { Infections in CF patients only } \\
\text { Environment: soil, rhizosphere, and river water } \\
\text { Biocontrol agent }\end{array}$ \\
\hline B. ubonensis & Genomovar $\mathrm{X}$ & $\begin{array}{l}\text { Infections in non-CF patients only } \\
\text { Environment: soil }\end{array}$ \\
\hline B. latens & BCC1 & Infections in CF patients only \\
\hline B. diffusa & BCC2 & $\begin{array}{l}\text { Infections in CF and non-CF patients } \\
\text { Environment: soil and water }\end{array}$ \\
\hline B. arboris & $\mathrm{BCC} 3$ & $\begin{array}{l}\text { Infections in CF and non-CF patients } \\
\text { Environment: soil rhizosphere, plant, river water, and industrial } \\
\text { contaminant }\end{array}$ \\
\hline B. seminalis & $\mathrm{BCC} 7$ & $\begin{array}{l}\text { Infections in CF and non-CF patients } \\
\text { Environment: soil, rhizosphere, and plant }\end{array}$ \\
\hline B. metallica & BCC8 & Infections in CF patients only \\
\hline B. contaminans & Group K (BCC AT) & $\begin{array}{l}\text { Infections in CF patients and sheep } \\
\text { Environment: plant }\end{array}$ \\
\hline B. lata & Group K & $\begin{array}{l}\text { Infections in CF and non-CF patients } \\
\text { Environment: forest soil, rhizosphere, plant, river water, and contaminant }\end{array}$ \\
\hline
\end{tabular}

Abbreviation: CF, cystic fibrosis.

${ }^{a}$ Adapted with permission from Sousa et al, ${ }^{3}$ Vandamme and Dawyndt, ${ }^{78}$ and Drevinek and Mahenthiralingam. ${ }^{79}$

bInfections in non-CF patients include reports in immunocompromised patients (malignancy, HIV, and chronic granulomatous disease), immunocompetent individuals (chronic suppurative otitis media, pharyngeal infections, and pediatric neck infections), and hospital-acquired infections in patients with comorbidities (chronic hemodialysis, diabetes mellitus, and congestive heart failure) or those undergoing interventions (prolonged stay in intensive care units, use of central venous catheters, indwelling urinary catheters, and endotracheal tubes) or in the setting of a nosocomial outbreak.

agents of soil bioremediation and phytoremediation. ${ }^{31-33}$ However, the concern to human health is whether the agricultural use of these organisms may present a risk as reservoirs for antibiotic resistance genes. Their ability to multiply in the soil and rhizosphere of plants may be reason enough to consider restricting plants from high-risk patient groups within hospitals (e.g., immunocompromised or CF wards). ${ }^{34-36}$

\section{Identification and Antibiotic Susceptibility Testing}

All three organisms have similar growth requirements, can have a similar appearance on standard media, and all can be potentially misidentified as each other and as Pseudomonas species. - Table 2 outlines the basic microbiological characteristics of these organisms. Automated identification using 


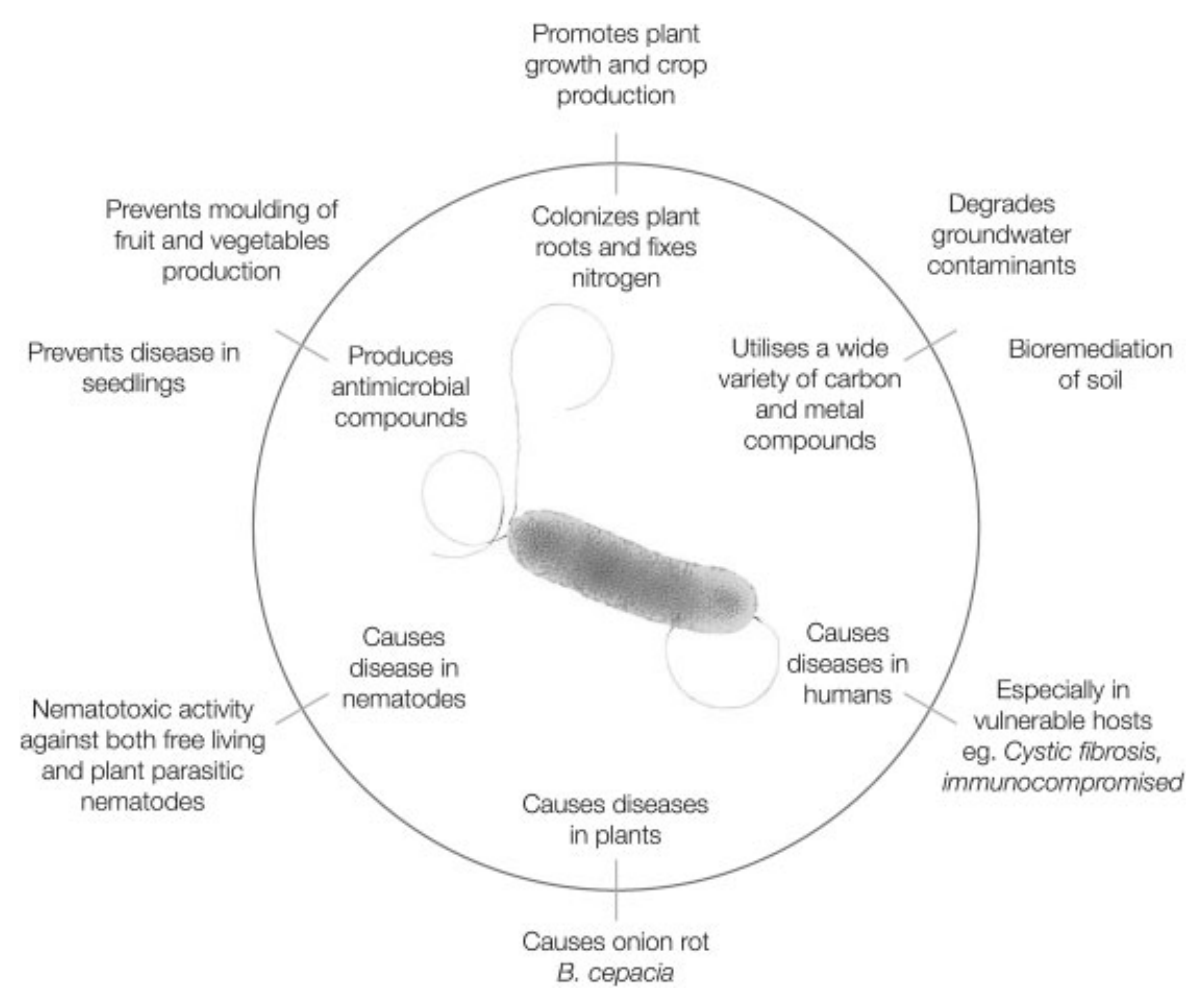

Fig. 2 Beyond human pathogens: biotechnological uses. Adapted with permission from Mahenthiralingam et al ${ }^{32}$ and Ryan et al ${ }^{31}$. (Colored transmission electron micrograph of S. maltophilia reprinted with permission from Owens B. Silver makes antibiotics thousands of times more effective. Nature News. Macmillan Publishers Ltd, June 19, 2013. Accessed August 9, 2014. Available at http://www.nature.com/news/silvermakes-antibiotics-thousands-of-times-more-effective-1.13232). ${ }^{99}$

biochemical differentiation (such as API 20 NE [bioMérieux, Marcy l'Etoile, France] and Vitek-2 [bioMérieux, Marcy l'Etoile, France]) can demonstrate low discrimination and misidentifications, especially with CF patient samples. ${ }^{37-40}$ Modern laboratory identification techniques, such as matrixassisted laser desorption ionization, time-of-flight mass spectrometry (MALDI-TOF MS) appears to identify and discriminate these organisms well, even with specimens from $\mathrm{CF}$ patients. ${ }^{41-43}$ The ability for current versions of MALDI-TOF

Table 2 Microbiology characteristics of Stenotrophomonas maltophilia, Burkholderia cepacia complex, and Achromobacter xylosoxidans

\begin{tabular}{|l|}
\hline Aerobic \\
\hline $\begin{array}{l}\text { Nonfermenting gram-negative rod } \\
\text { Appears as a nonlactose fermenting organism } \\
\text { on MacConkey agar }\end{array}$ \\
\hline Motile \\
\hline Catalase positive \\
\hline $\begin{array}{l}\text { Oxidase positive } \\
\text { Except S. maltophilia which is most often oxidase } \\
\text { negative (although reported to be oxidase } \\
\text { positive in 20\%) }\end{array}$ \\
\hline Indole negative \\
\hline $\mathrm{H}_{2} \mathrm{~S}$ negative \\
\hline Urease negative \\
\hline
\end{tabular}

MS instruments to routinely discriminate between the species within the $B$. cepacia complex requires further work, but importantly does appear to accurately identify B. cenocepacia. $^{44}$ When compared with polymerase chain reaction-restriction fragment length polymorphism (PCR-RFLP) analysis of the recA gene, the Microflex LT MALDI-TOF (Bruker Daltonics GmbH, Leipzig, Germany), under the control of the FlexControl 3.0 software (Bruker Daltonics $\mathrm{GmbH}$ ) and analyzed by Biotyper 2.0 software (Bruker Daltronics $\mathrm{GmbH}$ ), produced corresponding discriminatory results, although only the PCR-RFLP method provided a fine discrimination into two lineages (IIIA and IIIB). ${ }^{45}$

A remarkable feature common to these three organisms is the vast array of intrinsic and acquired mechanisms of antibiotic resistance. Intrinsic $\beta$-lactamases, a wide range of efflux pump systems, enzymatic modifications, changes in the outer membrane and target site modification are just several of the mechanisms harbored by these organisms. - Table 3 outlines these mechanisms in more detail, which may or may not be present in every isolate. Importantly, however, is the ability of these organisms to acquire new resistance determinants (e.g., Sul1 integron that causes trimethoprim-sulfamethoxazole resistance in S. maltophilia) and to rapidly induce resistance (e.g., with the use of fluoroquinolones).

Intrinsic antibiotic resistance patterns in S. maltophilia, $B$. cepacia complex, and A. xylosoxidans are important for physicians to consider when deciding on empiric therapy. Furthermore, this information assists clinical microbiology laboratories with antibiotic susceptibility testing and the 
Table 3 Mechanisms of antibiotic resistance

\begin{tabular}{|c|c|c|c|}
\hline Organism & Category & Resistance mechanism & Antimicrobial affected \\
\hline \multirow[t]{5}{*}{ S. maltophilia ${ }^{1,80}$} & $\beta$-lactamases & $\begin{array}{l}\text { Two chromosomal induc- } \\
\text { ible } \beta \text {-lactamases } \\
\text { - L1 (class B) MBL; L2 } \\
\text { (class A) serine } \\
\text { Plasmid ESBL } \\
\text { - TEM-2 penicillinase; } \\
\text { CTX-M }\end{array}$ & Hydrolyses all $\beta$-lactams \\
\hline & Efflux systems & $\begin{array}{l}\text { Multidrug efflux systems } \\
\text { - SmeDEF; SmeABC; SmrA }\end{array}$ & $\begin{array}{l}\text { Resistance to tetracycline } \\
\text { class, chloramphenicol, } \\
\text { erythromycin and fluoro- } \\
\text { quinolone class }\end{array}$ \\
\hline & $\begin{array}{l}\text { Enzymatic } \\
\text { modification }\end{array}$ & $\begin{array}{l}\text { Aminoglycoside-modify- } \\
\text { ing enzymes } \\
\text { Smqnr topoisomerase } \\
\text { enzyme }\end{array}$ & $\begin{array}{l}\text { Resistance to aminoglyco- } \\
\text { sides andlow level intrinsic } \\
\text { quinolones }\end{array}$ \\
\hline & $\begin{array}{l}\text { Changes in the outer } \\
\text { membrane }\end{array}$ & $\begin{array}{l}\text { Phosphoglucomutase } \\
\text { (SpgM) }\end{array}$ & $\begin{array}{l}\text { Aminoglycosides, polymyxin } \\
\text { B and fluoroquinolones }\end{array}$ \\
\hline & $\begin{array}{l}\text { Target site } \\
\text { modification }\end{array}$ & $\begin{array}{l}\text { Protect DNA gyrase and } \\
\text { topoisomerases (Smgnr); } \\
\text { Class } 1 \text { integrons (Sul1 } \\
\text { and Sul2) }\end{array}$ & $\begin{array}{l}\text { Resistance to fluoroquino- } \\
\text { lones; resistance to TMP-SMX }\end{array}$ \\
\hline \multirow[t]{5}{*}{ B. cepacia complex $9,32,81-84$} & $\beta$-lactamases & $\begin{array}{l}\text { Chromosomal, inducible } \\
\text { Ambler class C (PenA); } \\
\text { plus others (Ambler class } \\
\text { A + D) }\end{array}$ & $\beta$-lactams \\
\hline & Efflux systems & $\begin{array}{l}\text { RND family efflux } \\
\text { transporter }\end{array}$ & $\begin{array}{l}\text { Aminoglycosides, ciproflox- } \\
\text { acin, trimethoprim, } \\
\text { chloramphenicol }\end{array}$ \\
\hline & $\begin{array}{l}\text { Enzymatic } \\
\text { modification }\end{array}$ & $\begin{array}{l}\text { Aminoglycoside-modify- } \\
\text { ing enzymes; Dihydrofo- } \\
\text { late reductase }\end{array}$ & $\begin{array}{l}\text { Resistance to aminoglyco- } \\
\text { sides, trimethoprim }\end{array}$ \\
\hline & $\begin{array}{l}\text { Changes in outer } \\
\text { membrane }\end{array}$ & $\begin{array}{l}\text { Lack of binding sites on } \\
\text { the lipopolysaccharide } \\
\text { layer }\end{array}$ & $\begin{array}{l}\text { Intrinsic resistance to the } \\
\text { cationic antimicrobials, pol- } \\
\text { ymyxins, and } \\
\text { aminoglycosides }\end{array}$ \\
\hline & Altered target site & $\begin{array}{l}\text { Change in penicillin bind- } \\
\text { ing proteins; Mutations in } \\
\text { the quinolone resistance- } \\
\text { determining region, } \\
\text { QRDR (gyrAand parC) }\end{array}$ & $\beta$-lactams; fluoroquinolones \\
\hline \multirow[t]{3}{*}{ A. xylosoxidans ${ }^{73,85-88}$} & $\beta$-lactamases & $\begin{array}{l}\text { Intrinsic OXA } \mathrm{OX}_{114}, \mathrm{OXA}_{243} \text {, } \\
\text { and } \mathrm{OXA}_{2} ; \text { Cephalospori- } \\
\text { nase, bla } a_{a m p c} ; \text { Acquired } \\
\left.\text { carbapenemases (bla } a_{\mathrm{IMP}}\right)\end{array}$ & $\beta$-lactams \\
\hline & Efflux systems & $\begin{array}{l}\text { RNA-type multidrug efflux } \\
\text { pumps; AxyABM and } \\
\text { AxyXY-OprZ }\end{array}$ & $\begin{array}{l}\text { Decreased MICs of cephalo- } \\
\text { sporins (except cefepime), } \\
\text { aztreonam, fluoroquino- } \\
\text { lones, chloramphenicol. In- } \\
\text { nate aminoglycoside } \\
\text { resistance and extrudes ce- } \\
\text { fepime, carbapenems, some } \\
\text { fluoroquinolones, tetracy- } \\
\text { clines, and erythromycin }\end{array}$ \\
\hline & $\begin{array}{l}\text { Enzymatic } \\
\text { modification }\end{array}$ & $\begin{array}{l}\text { Aminoglycoside modify- } \\
\text { ing enzymes, AAC }\left(6^{\prime}\right)-\mathrm{Ib} \\
\text { and aadA1 }\end{array}$ & Aminoglycosides \\
\hline
\end{tabular}

Abbreviations: ESBL, extended spectrum $\beta$-lactamase; MBL, metallo $\beta$-lactamase; RND, resistance nodulation division; TMP-SMX, trimethoprimsulfamethoxazole. 
Table 4 Intrinsic antibiotic resistance

\begin{tabular}{|c|c|c|c|c|c|c|}
\hline & \multicolumn{2}{|c|}{ S. maltophilia } & \multicolumn{2}{|c|}{ B. cepacia complex } & \multicolumn{2}{|c|}{ A. xylosoxidans } \\
\hline & EUCAST & CLSI & EUCAST & CLSI & EUCAST & Other $^{2}$ \\
\hline Amoxicillin-clavulanate & $R$ & $R$ & $R$ & $R$ & - & $R$ \\
\hline Ticarcillin-clavulanate & - & - & $R$ & $n / r$ & - & - \\
\hline Piperacillin-tazobactam & $R$ & $R$ & - & $R$ & - & - \\
\hline Ceftriaxone & $R$ & $R$ & - & $R$ & $R$ & $R$ \\
\hline Ceftazidime & $R$ & - & - & - & - & - \\
\hline Cefepime & $R$ & - & $n / r$ & $R$ & $n / r$ & $R$ \\
\hline Aztreonam & $R$ & $R$ & $n / r$ & $R$ & $n / r$ & $R$ \\
\hline Ertapenem & $R$ & $R$ & $R$ & $R$ & $R$ & $R$ \\
\hline Imipenem & $R$ & $R$ & $R$ & $R$ & - & - \\
\hline Meropenem & $R$ & $R$ & - & - & - & - \\
\hline Ciprofloxacin & - & $n / r$ & $\mathrm{R}$ & $n / r$ & - & $R$ \\
\hline Aminoglycoside & $R$ & $R$ & $R$ & $R$ & - & $R$ \\
\hline Trimethoprim & $R$ & $R$ & $R$ & $R$ & - & $R$ \\
\hline Trimethoprim-sulfamethoxazole & - & - & - & - & - & - \\
\hline Fosfomycin & $R$ & $\mathrm{R}$ & $\mathrm{R}$ & $\mathrm{R}$ & - & $R$ \\
\hline Minocycline/Tigecycline & - & - & - & - & - & - \\
\hline Colistin & - & - & $R$ & $R$ & - & - \\
\hline Chloramphenicol & - & - & $R$ & - & - & - \\
\hline
\end{tabular}

Abbreviations: CLSI, Clinical and Laboratory Standards Institute ${ }^{46}$; EUCAST, European Committee on Antimicrobial Susceptibility Testing ${ }^{47}$; $\mathrm{n} / \mathrm{r}$, not reported.

antrinsic resistance patterns for $A$. xylosoxidans gathered from other reports in the literature. ${ }^{27,70,71,73,88-90}$

reporting of results (see - Table 4). There are subtle differences between intrinsic resistance reports by Clinical and Laboratory Standards Institute (CLSI; M100-S24, appendixB. 2$)^{46}$ and European Committee on Antimicrobial Susceptibility Testing (EUCAST) ${ }^{47}$ and for A. xylosoxidans there is only limited guidance from EUCAST alone, with additional information gathered from other reports in the literature.

Clinical breakpoints are limited for these three organisms. It should also be noted that clinical breakpoints provided are based on achievable blood levels of antimicrobials, which may not reflect what can be achieved in the lung, especially in the setting of aerosolized antimicrobials. ${ }^{48}$ EUCAST provides clinical breakpoints only for S. maltophilia and only for trimethoprim-sulfamethoxazole. Caution is required in the interpretation of trimethoprim-sulfamethoxazole susceptibility testing by disc diffusion or by a gradient strip method (e. g., Etest [bioMérieux, Marcy l'Etoile, France]) as results should be read at $80 \%$ inhibition given the bacteriostatic action of the antibiotic causing a leading edge of growth. EUCAST state that results for other agents should be treated with caution given the lack of data to support a relationship between susceptibility and clinical outcome. CLSI recommends first-line reporting of trimethoprim-sulfamethoxazole, and second line reporting of ticarcillin-clavulanate, ceftazidime, minocycline, levofloxacin, and chloramphenicol. It should be noted that EUCAST considers S. maltophilia to be intrinsically resistant to ceftazidime.
CLSI provides clinical breakpoints for B. cepacia complex and recommends first-line testing of trimethoprimsulfamethoxazole, and second line testing of ticarcillinclavulanate, ceftazidime, meropenem, minocycline, levofloxacin, and chloramphenicol. In contrast, EUCAST recently tried to address their lack of clinical breakpoints for B. cepacia complex, however, determined that there was no evidence to describe a relationship for minimum inhibitory concentration (MIC) and outcome, and were unable to provide guidance. They describe the MIC distributions for relevant antimicrobials to be wide and that susceptibility testing was not reproducible using a routine methodology (i.e., MIC determination by the gradient strip method). A Cochrane review ${ }^{49}$ in September 2012 also concluded with similar findings, highlighting that they did not find any randomized controlled trials that compared treatments for exacerbations in $\mathrm{CF}$ patients who were infected with $B$. cepacia complex. They concluded that no conclusions could be drawn from their review and clinicians should continue to assess each patient individually, taking into account in vitro antibiotic susceptibility data, previous clinical responses and their own experience. It should be noted that EUCAST consider B. cepacia complex to be intrinsically resistant to ticarcillin-clavulanate but not piperacillin-tazobactam, while in comparison, CLSI reports intrinsic resistance to piperacillin-tazobactam, do not list ticarcillin-clavulanate in their intrinsic resistance appendix, and do provide clinical breakpoints. 


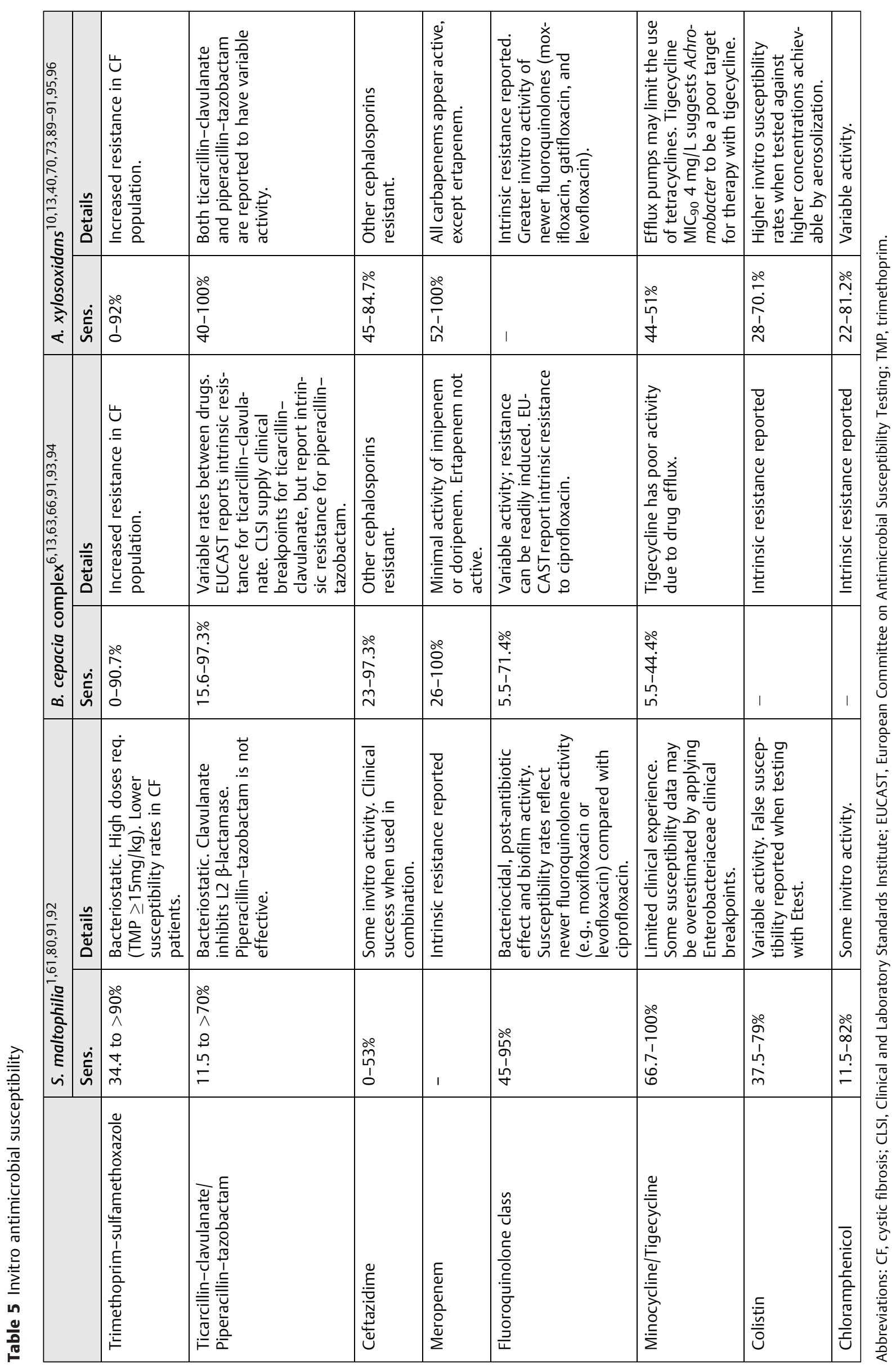


Relating to A. xylosoxidans, EUCAST does not provide specific guidance beyond their nonspecies-related breakpoints. CLSI provides clinical breakpoints under the section "Other Non-Enterobacteriaceae," although their specific relevance to A. xylosoxidans is debatable.

\section{Management of Infections}

The first challenge regarding management is to establish the clinical significance of culturing one of these nonfermenters from a clinical specimen. This question is largely irrelevant if these organisms are identified from sterile sites (e.g., cerebrospinal fluid, blood, and joint aspiration), but when they are identified either alone or with other organisms from nonsterile sites (e.g., sputum, wound swabs, and urine cultures), their role in disease may be difficult to ascertain. However, the repeated isolation of these organisms in the context of clinical disease or in unwell patients, antimicrobial therapy directed against these nonfermenters is often warranted. For example, A. xylosoxidans can cause a level of inflammation similar to $P$. aeruginosa in chronically infected CF patients and therefore should be treated accordingly. ${ }^{50}$

Recommendations on specific antibiotic agents for treatment are difficult given the lack of reproducible susceptibility results and minimal clinical data. The fact that these organisms are also frequently part of a mixed infection, especially when it comes to pulmonary involvement, adds to the complexity of management. Reported rates of in vitro antibiotic resistance are very broad depending on patient type and location (see - Table 5). In general, isolates from CF patients demonstrate higher rates of resistance than those found in other patient groups.

The suggested first- and second-line agents for treatment, as well as combination therapy options are outlined in - Table 6. Individual susceptibility results, patient allergy, and other concurrent conditions will also influence the choice of agent.

\section{S. maltophilia}

Trimethoprim-sulfamethoxazole remains the first-line therapy for S. maltophilia. On the basis of in vitro pharmacodynamics modelling and the bacteriostatic action of trimethoprim-sulfamethoxazole, it is recommended that a higher dose be used (daily dose of $15 \mathrm{mg}$ per $\mathrm{kg}$ of the trimethoprim component, split 6 to 8 hourly), ${ }^{51,52}$ which is more similar to the dose chosen for the treatment of Pneumocystis jirovecii pneumonia. In the setting of trimethoprimsulfamethoxazole resistance, second line agents are available and are often used in combination (see - Table 6). ${ }^{53}$ S. maltophilia is inherently resistant to carbapenems, and in fact, use of this class of antibiotic often selects for S. maltophilia in patients who are heavily immunosuppressed (e.g.,

Table 6 Suggested treatment options

\begin{tabular}{|c|c|c|c|c|}
\hline Organism & First line & Second line & Combination & $\begin{array}{l}\text { Alternative } \\
\text { combination }\end{array}$ \\
\hline S. maltophilia & $\begin{array}{l}\text { Trimethoprim- } \\
\text { sulfamethoxazole }\end{array}$ & $\begin{array}{l}\text { Moxifloxacin/levofloxacin } \\
\text { Ticarcillin-clavulanate } \\
\text { Minocycline/tigecycline }{ }^{a} \\
\text { Colistin ( } \pm \text { rifampicin) }\end{array}$ & $\begin{array}{l}\text { Trimethoprim- } \\
\text { sulfamethoxazole } \\
\text { PLUS } \\
\text { Any 2nd line agent, } \\
\text { or ceftazidime }\end{array}$ & $\begin{array}{l}\text { Ticarcillin-clavulanate } \\
\text { PLUS } \\
\text { Aztreonam } \\
\text { PLUS } \\
\text { Moxifloxacin/ } \\
\text { levofloxacin }\end{array}$ \\
\hline B. cepacia complex & $\begin{array}{l}\text { Trimethoprim- } \\
\text { sulfamethoxazole } \\
\text { Ceftazidime } \\
\text { Meropenem }\end{array}$ & $\begin{array}{l}\text { Minocycline } \\
\text { Chloramphenicol } \\
\text { Ciprofloxacin }{ }^{\mathrm{b}} \\
\text { Piperacillin-tazobactam } \\
\text { Ticarcillin-clavulanate }\end{array}$ & $\begin{array}{l}\text { Combination of any } \\
1 \text { st line or } 2 \text { nd } \\
\text { lines agents }\end{array}$ & $\begin{array}{l}\text { Meropenem } \\
\text { PLUS } \\
\text { Ceftazidime } \\
\text { PLUS } \\
\text { Ciprofloxacin } \\
\text { PLUS } \\
\text { Minocycline, or } \\
\text { amikacin } \\
\text { PLUS } \\
\text { Tobramycin (inhaled }{ }^{c} \text { ) }\end{array}$ \\
\hline A. xylosoxidans & $\begin{array}{l}\text { Piperacillin-tazobactam } \\
\text { Meropenem } \\
\text { Trimethoprim- } \\
\text { sulfamethoxazole }\end{array}$ & $\begin{array}{l}\text { Ceftazidime } \\
\text { Minocycline } \\
\text { Colistin } \\
\text { Chloramphenicol }\end{array}$ & $\begin{array}{l}\text { Meropenem } \\
\text { PLUS } \\
\text { Ciprofloxacin/ } \\
\text { levofloxacind }^{\text {d }}\end{array}$ & $\begin{array}{l}\text { Meropenem } \\
\text { PLUS } \\
\text { Minocycline, or } \\
\text { levofloxacin } \\
\text { PLUS } \\
\text { Chloramphenicol } \\
\text { PLUS } \\
\text { Colistin (inhaled }^{\mathrm{C}} \text { ) }\end{array}$ \\
\hline
\end{tabular}

${ }^{a}$ Caution should be applied with the use of tigecycline given the 2010 and 2013 US FDA drug safety communications warning not to use tigecycline in pulmonary infections, especially hospital-acquired and ventilator-associated pneumonia, because of increased mortality risk. ${ }^{97,98}$

bECAST report $B$. cepacia complex to be intrinsically resistance to ciprofloxacin.

'Inhaled antibiotics have been recommended primarily in pulmonary exacerbations of CF.

'Use of newer fluoroquinolones are preferred when used in combination, in preference to ciprofloxacin, given the greater invitro activity, ${ }^{13}$ although intrinsic resistance and poor activity is widely reported across the class. ${ }^{70}$ 
neutropenic patients). The inclusion of a specific biofilm active agent, such as moxifloxacin or levofloxacin has also been shown to be of benefit, ${ }^{23,54,55}$ although caution should be applied when used as monotherapy because of the risk of rapid induction of resistance. ${ }^{56-58}$ Minocycline and tigecycline have also shown some promise to assist with the treatment of S. maltophilia. ${ }^{59,60}$ The evidence for combination therapy often comes from in vitro synergy testing data, and highlights the need for further research into optimal therapy for this troublesome organism. The combinations are often reported involving trimethoprim-sulfamethoxazole, ticarcillin-clavulanate, moxifloxacin, levofloxacin, aztreonam, ceftazidime, colistin, rifampicin, tigecycline, and minocycline. ${ }^{53,59,61}$

\section{B. cepacia Complex}

Similar principles apply as for treatment of $S$. maltophilia. Trimethoprim-sulfamethoxazole remains a recommended first-line therapy. Higher dosing schedules (15 mg per $\mathrm{kg}$ of the trimethoprim component, split 6 to 8 hourly) has again been recommended based on pharmacokinetic and pharmacodynamics data in the critically ill, ${ }^{52}$ as well as extrapolated data from $B$. pseudomallei, the pathogen causing melioidosis. ${ }^{62}$ In contrast to S. maltophilia, B. cepacia complex are often sensitive to meropenem, which is another first-line therapy, but are inherently resistant to polymyxin and colistin. Tigecycline demonstrates poor activity against B. cepacia complex owing to drug efflux, although minocycline maintains activity. ${ }^{16,63-65}$ Combination therapy is often used for patients who are more severely unwell, and includes double and triple combinations of first- and second-line agents (see - Table 6). The main alternative therapeutic agents beyond trimethoprim-sulfamethoxazole include ceftazidime and meropenem, either alone or in combination, or with other antimicrobial agents. ${ }^{66}$ The role of penicillins, namely, piperacillin-tazobactam and ticarcillin-clavulanate remains controversial given the different intrinsic resistance reports between EUCAST and CLSI, as previously mentioned. Inhaled tobramycin has the potential to achieve high pulmonary concentrations to inhibit $B$. cepacia isolates, despite widespread resistance reported. ${ }^{67,68}$ As mentioned, CF patients proceeding to lung transplantation, who are colonized or infected with B. cepacia complex (particularly with B. cenocepacia) are at high risk for a poor outcome, manifested by an overwhelming "cepacia syndrome."6,7 The highest risk for this is within 3months following transplant and many lung transplant centers around the world have B. cenocepacia as an absolute contraindication to transplant. If transplantation is performed in the setting of $B$. cepacia complex colonization or infection, aggressive combination (double and triple) therapy is often used perioperatively. ${ }^{69}$

\section{A. xylosoxidans}

Less is known about the optimal therapy for Achromobacter spp. In addition to the recognized intrinsic antibiotic resistance patterns, acquired resistance is also widely reported. Given the limitations of the clinical microbiology laboratory to interpret antimicrobial susceptibility results, close com- munication between the treating doctors and the laboratory is required. The most active agents are piperacillin-tazobactam, meropenem, and trimethoprim-sulfamethoxazole, whereas ceftazidime is more active than cefepime. ${ }^{13,70-72}$ Tetracyclines (e.g., minocycline) have variable activity and may be vulnerable to a multidrug efflux pump. ${ }^{73}$ Although specifically for tigecycline, an $\mathrm{MIC}_{90}$ of $4 \mathrm{mg} / \mathrm{L}$ has been reported in CF patients, suggesting Achromobacter to be a poor target for therapy with tigecycline. ${ }^{71}$ Aminoglycosides, fluoroquinolones, fosfomycin, and aztreonam all have poor activity. Multidrug-resistant phenotypes and carbapenemase-producing isolates have been reported, especially for the $\mathrm{CF}$ patient population, further complicating therapeutic options. $^{10,26,74}$ Combination therapy has been recommended for the treatment of $A$. xylosoxidans pulmonary exacerbations in $\mathrm{CF}^{75}$ Although the use of concurrent inhaled antibiotics, such as inhaled colistin, could also be considered. $^{71,76,77}$

\section{Conclusions}

S. maltophilia, B. cepacia complex, and A. xylosoxidans are remarkable organisms with the ability to live and thrive in hostile environments, including withstanding antibiotic treatment. The widespread use of fluoroquinolones, aminoglycosides, and broad-spectrum $\beta$-lactam antimicrobials has created the perfect niche for these opportunistic pathogens. Coinfection with Pseudomonas species, interspecies quorumsensing and survival within biofilms create unique therapeutic challenges. Successful treatment requires a greater understanding of the clinical consequences of infections with these organisms, together with their innate microbiological characteristics and antimicrobial resistance patterns. At this stage, more clinical data are required to assist with treatment recommendations, and future research should focus on the role of combination therapy.

\section{Acknowledgments}

A.Y.P. acknowledges support from an Australian National Health and Medical Research Council Career Development Fellowship (APP1047916).

\section{References}

1 Brooke JS. Stenotrophomonas maltophilia: an emerging global opportunistic pathogen. Clin Microbiol Rev 2012;25(1):2-41

2 Svensson-Stadler LA, Mihaylova SA, Moore ER. Stenotrophomonas interspecies differentiation and identification by gyrB sequence analysis. FEMS Microbiol Lett 2012;327(1):15-24

3 Sousa SA, Ramos CG, Leitão JH. Burkholderia cepacia complex: emerging multihost pathogens equipped with a wide range of virulence factors and determinants. Int J Microbiol 2011. doi: $10.1155 / 2011 / 607575$

4 Mahenthiralingam E, Bischof J, Byrne SK, et al. DNA-based diagnostic approaches for identification of Burkholderia cepacia complex, Burkholderia vietnamiensis, Burkholderia multivorans, Burkholderia stabilis, and Burkholderia cepacia genomovars I and III. J Clin Microbiol 2000;38(9):3165-3173 
5 Vandamme P, Holmes B, Coenye T, et al. Burkholderia cenocepacia sp. nov.-a new twist to an old story. Res Microbiol 2003;154(2): 91-96

6 Lynch JP III. Burkholderia cepacia complex: impact on the cystic fibrosis lung lesion. Semin Respir Crit Care Med 2009;30(5): 596-610

7 Alexander BD, Petzold EW, Reller LB, et al. Survival after lung transplantation of cystic fibrosis patients infected with Burkholderia cepacia complex. Am J Transplant 2008;8(5):1025-1030

8 Manno G, Dalmastri C, Tabacchioni S, et al. Epidemiology and clinical course of Burkholderia cepacia complex infections, particularly those caused by different Burkholderia cenocepacia strains, among patients attending an Italian Cystic Fibrosis Center. J Clin Microbiol 2004;42(4):1491-1497

9 Drevinek P, Mahenthiralingam E. Burkholderia cenocepacia in cystic fibrosis: epidemiology and molecular mechanisms of virulence. Clin Microbiol Infect 2010;16(7):821-830

10 Lambiase A, Catania MR, Del Pezzo M, et al. Achromobacter xylosoxidans respiratory tract infection in cystic fibrosis patients. Eur J Clin Microbiol Infect Dis 2011;30(8):973-980

11 Barrado L, Brañas P, Orellana MA, et al. Molecular characterization of Achromobacter isolates from cystic fibrosis and non-cystic fibrosis patients in Madrid, Spain. J Clin Microbiol 2013;51(6): 1927-1930

12 Ridderberg W, Wang M, Nørskov-Lauritsen N. Multilocus sequence analysis of isolates of Achromobacter from patients with cystic fibrosis reveals infecting species other than Achromobacter xylosoxidans. J Clin Microbiol 2012;50(8):2688-2694

13 Sader HS, Jones RN. Antimicrobial susceptibility of uncommonly isolated non-enteric Gram-negative bacilli. Int J Antimicrob Agents 2005;25(2):95-109

14 Safdar A, Rolston KV. Stenotrophomonas maltophilia: changing spectrum of a serious bacterial pathogen in patients with cancer. Clin Infect Dis 2007;45(12):1602-1609

15 Porter S, Ketheesan N, Norton R. Bacteraemias in tropical Australia: changing trends over a 10 -year period. Diagn Microbiol Infect Dis 2013;75(3):266-270

16 Parkins MD, Elborn JS. Newer antibacterial agents and their potential role in cystic fibrosis pulmonary exacerbation management. J Antimicrob Chemother 2010;65(9):1853-1861

17 Millar FA, Simmonds NJ, Hodson ME. Trends in pathogens colonising the respiratory tract of adult patients with cystic fibrosis, 1985-2005. J Cyst Fibros 2009;8(6):386-391

18 Kidd TJ, Douglas JM, Bergh HA, Coulter C, Bell SC. Burkholderia cepacia complex epidemiology in persons with cystic fibrosis from Australia and New Zealand. Res Microbiol 2008;159(3):194-199

19 Spilker T, Vandamme P, Lipuma JJ. Identification and distribution of Achromobacter species in cystic fibrosis. J Cyst Fibros 2013; 12(3):298-301

20 Saiman L, Siegel J. Infection control in cystic fibrosis. Clin Microbiol Rev 2004;17(1):57-71

21 Barchitta M, Cipresso R, Giaquinta L, et al. Acquisition and spread of Acinetobacter baumannii and Stenotrophomonas maltophilia in intensive care patients. Int J Hyg Environ Health 2009;212(3): 330-337

22 Pereira RH, Carvalho-Assef AP, Albano RM, et al. Achromobacter xylosoxidans: characterization of strains in Brazilian cystic fibrosis patients. J Clin Microbiol 2011;49(10):3649-3651

23 Di Bonaventura G, Spedicato I, D’Antonio D, Robuffo I, Piccolomini R. Biofilm formation by Stenotrophomonas maltophilia: modulation by quinolones, trimethoprim-sulfamethoxazole, and ceftazidime. Antimicrob Agents Chemother 2004;48(1):151-160

24 de Oliveira-Garcia D, Dall'Agnol M, Rosales M, Azzuz AC, Martinez MB, Girón JA. Characterization of flagella produced by clinical strains of Stenotrophomonas maltophilia. Emerg Infect Dis 2002; 8(9):918-923

25 Van Acker H, Sass A, Bazzini S, et al. Biofilm-grown Burkholderia cepacia complex cells survive antibiotic treatment by avoiding production of reactive oxygen species. PLoS ONE 2013;8(3): e58943

26 Trancassini M, Iebba V, Citerà N, et al. Outbreak of Achromobacter xylosoxidans in an Italian Cystic fibrosis center: genome variability, biofilm production, antibiotic resistance, and motility in isolated strains. Front Microbiol 2014;5:138

27 Jakobsen TH, Hansen MA, Jensen PO, et al. Complete genome sequence of the cystic fibrosis pathogen Achromobacter xylosoxidans NH44784-1996 complies with important pathogenic phenotypes. PLoS ONE 2013;8(7):e68484

28 Kataoka D, Fujiwara H, Kawakami T, et al. The indirect pathogenicity of Stenotrophomonas maltophilia. Int J Antimicrob Agents 2003;22(6):601-606

29 Ryan RP, Fouhy Y, Garcia BF, et al. Interspecies signalling via the Stenotrophomonas maltophilia diffusible signal factor influences biofilm formation and polymyxin tolerance in Pseudomonas aeruginosa. Mol Microbiol 2008;68(1):75-86

30 Wiley L, Bridge DR, Wiley LA, Odom JV, Elliott T, Olson JC. Bacterial biofilm diversity in contact lens-related disease: emerging role of Achromobacter, Stenotrophomonas, and Delftia. Invest Ophthalmol Vis Sci 2012;53(7):3896-3905

31 Ryan RP, Monchy S, Cardinale M, et al. The versatility and adaptation of bacteria from the genus Stenotrophomonas. Nat Rev Microbiol 2009;7(7):514-525

32 Mahenthiralingam E, Urban TA, Goldberg JB. The multifarious, multireplicon Burkholderia cepacia complex. Nat Rev Microbiol 2005;3(2):144-156

33 Hayat R, Ali S, Amara U, Khalid R, Ahmed I. Soil beneficial bacteria and their role in plant growth promotion: a review. Ann Microbiol 2010;60:579-598

34 Walsh F, Duffy B. The culturable soil antibiotic resistome: a community of multi-drug resistant bacteria. PLoS ONE 2013; 8(6):e65567

35 Allen HK, Donato J, Wang HH, Cloud-Hansen KA, Davies J, Handelsman J. Call of the wild: antibiotic resistance genes in natural environments. Nat Rev Microbiol 2010;8(4):251-259

36 Amoureux L, Bador J, Fardeheb S, et al. Detection of Achromobacter xylosoxidans in hospital, domestic, and outdoor environmental samples and comparison with human clinical isolates. Appl Environ Microbiol 2013;79(23):7142-7149

37 Bosshard PP, Zbinden R, Abels S, Böddinghaus B, Altwegg M, Böttger EC. 16S rRNA gene sequencing versus the API $20 \mathrm{NE}$ system and the VITEK 2 ID-GNB card for identification of nonfermenting Gram-negative bacteria in the clinical laboratory. J Clin Microbiol 2006;44(4):1359-1366

38 Ferroni A, Sermet-Gaudelus I, Abachin E, et al. Use of 16S rRNA gene sequencing for identification of nonfermenting gram-negative bacilli recovered from patients attending a single cystic fibrosis center. J Clin Microbiol 2002;40(10):3793-3797

39 Coenye T, Vandamme P, Govan JR, LiPuma JJ. Taxonomy and identification of the Burkholderia cepacia complex. J Clin Microbiol 2001;39(10):3427-3436

40 Saiman L, Chen Y, Tabibi S, et al. Identification and antimicrobial susceptibility of Alcaligenes xylosoxidans isolated from patients with cystic fibrosis. J Clin Microbiol 2001;39(11):3942-3945

41 Clark AE, Kaleta EJ, Arora A, Wolk DM. Matrix-assisted laser desorption ionization-time of flight mass spectrometry: a fundamental shift in the routine practice of clinical microbiology. Clin Microbiol Rev 2013;26(3):547-603

42 Degand N, Carbonnelle E, Dauphin B, et al. Matrix-assisted laser desorption ionization-time of flight mass spectrometry for identification of nonfermenting gram-negative bacilli isolated from cystic fibrosis patients. J Clin Microbiol 2008;46(10):3361-3367

43 Marko DC, Saffert RT, Cunningham SA, et al. Evaluation of the Bruker Biotyper and Vitek MS matrix-assisted laser desorption ionizationtime of flight mass spectrometry systems for identification of nonfermenting gram-negative bacilli isolated from cultures from cystic fibrosis patients. J Clin Microbiol 2012;50(6):2034-2039 
44 Vanlaere E, Sergeant K, Dawyndt P, et al. Matrix-assisted laser desorption ionisation-time-of of-flight mass spectrometry of intact cells allows rapid identification of Burkholderia cepacia complex. J Microbiol Methods 2008;75(2):279-286

45 Lambiase A, Del Pezzo M, Cerbone D, Raia V, Rossano F, Catania MR. Rapid identification of Burkholderia cepacia complex species recovered from cystic fibrosis patients using matrix-assisted laser desorption ionization time-of-flight mass spectrometry. J Microbiol Methods 2013;92(2):145-149

46 CLSI. Performance Standards for Antimicrobial Susceptibility Testing; Twenty-Fourth Informational Supplement. CLSI document M100-524. Wayne PA. Clinical and Laboratory Standards Institute; 2014

47 Leclercq R, Cantón R, Brown DF, et al. EUCAST expert rules in antimicrobial susceptibility testing. Clin Microbiol Infect 2013; 19(2):141-160

48 Dudley MN, Loutit J, Griffith DC. Aerosol antibiotics: considerations in pharmacological and clinical evaluation. Curr Opin Biotechnol 2008;19(6):637-643

49 Horsley A, Jones AM. Antibiotic treatment for Burkholderia cepacia complex in people with cystic fibrosis experiencing a pulmonary exacerbation. Cochrane Database Syst Rev 2012;10: CD009529

50 Hansen CR, Pressler T, Nielsen KG, Jensen PO, Bjarnsholt T, Høiby N. Inflammation in Achromobacter xylosoxidans infected cystic fibrosis patients. J Cyst Fibros 2010;9(1):51-58

51 Zelenitsky SA, Iacovides H, Ariano RE, Harding GK. Antibiotic combinations significantly more active than monotherapy in an in vitro infection model of Stenotrophomonas maltophilia. Diagn Microbiol Infect Dis 2005;51(1):39-43

52 Brown GR. Cotrimoxazole - optimal dosing in the critically ill. Ann Intensive Care 2014;4:13

53 Falagas ME, Valkimadi PE, Huang YT, Matthaiou DK, Hsueh PR. Therapeutic options for Stenotrophomonas maltophilia infections beyond co-trimoxazole: a systematic review. J Antimicrob Chemother 2008;62(5):889-894

54 Pompilio A, Catavitello C, Picciani C, et al. Subinhibitory concentrations of moxifloxacin decrease adhesion and biofilm formation of Stenotrophomonas maltophilia from cystic fibrosis. J Med Microbiol 2010;59(Pt 1):76-81

55 Wu K, Yau YC, Matukas L, Waters V. Biofilm compared to conventional antimicrobial susceptibility of Stenotrophomonas maltophilia Isolates from cystic fibrosis patients. Antimicrob Agents Chemother 2013;57(3):1546-1548

56 Garrison MW, Anderson DE, Campbell DM, et al. Stenotrophomonas maltophilia: emergence of multidrug-resistant strains during therapy and in an in vitro pharmacodynamic chamber model. Antimicrob Agents Chemother 1996;40(12):2859-2864

57 Cho SY, Kang CI, Kim J, et al. Can levofloxacin be a useful alternative to trimethoprim-sulfamethoxazole for treating Stenotrophomonas maltophilia bacteremia? Antimicrob Agents Chemother 2014; 58(1):581-583

58 Wang YL, Scipione MR, Dubrovskaya Y, Papadopoulos J. Monotherapy with fluoroquinolone or trimethoprim-sulfamethoxazole for treatment of Stenotrophomonas maltophilia infections. Antimicrob Agents Chemother 2014;58(1):176-182

59 Church D, Lloyd T, Peirano G, Pitout J. Antimicrobial susceptibility and combination testing of invasive Stenotrophomonas maltophilia isolates. Scand J Infect Dis 2013;45(4):265-270

60 Farrell DJ, Sader HS, Jones RN. Antimicrobial susceptibilities of a worldwide collection of Stenotrophomonas maltophilia isolates tested against tigecycline and agents commonly used for S. maltophilia infections. Antimicrob Agents Chemother 2010; 54(6):2735-2737

61 Milne KE, Gould IM. Combination antimicrobial susceptibility testing of multidrug-resistant Stenotrophomonas maltophilia from cystic fibrosis patients. Antimicrob Agents Chemother 2012;56(8):4071-4077
62 Cheng AC, McBryde ES, Wuthiekanun V, et al. Dosing regimens of cotrimoxazole (trimethoprim-sulfamethoxazole) for melioidosis. Antimicrob Agents Chemother 2009;53(10):4193-4199

63 Zhou J, Chen Y, Tabibi S, Alba L, Garber E, Saiman L. Antimicrobial susceptibility and synergy studies of Burkholderia cepacia complex isolated from patients with cystic fibrosis. Antimicrob Agents Chemother 2007;51(3):1085-1088

64 Dixit D, Madduri RP, Sharma R. The role of tigecycline in the treatment of infections in light of the new black box warning. Expert Rev Anti Infect Ther 2014;12(4):397-400

65 Rajendran R, Quinn RF, Murray C, McCulloch E, Williams C, Ramage G. Efflux pumps may play a role in tigecycline resistance in Burkholderia species. Int J Antimicrob Agents 2010;36(2): 151-154

66 Avgeri SG, Matthaiou DK, Dimopoulos G, Grammatikos AP, Falagas ME. Therapeutic options for Burkholderia cepacia infections beyond co-trimoxazole: a systematic review of the clinical evidence. Int J Antimicrob Agents 2009;33(5):394-404

67 Trapnell BC, McColley SA, Kissner DG, et al; Phase 2 FTI Study Group. Fosfomycin/tobramycin for inhalation in patients with cystic fibrosis with pseudomonas airway infection. Am J Respir Crit Care Med 2012;185(2):171-178

68 Safdar A, Shelburne SA, Evans SE, Dickey BF. Inhaled therapeutics for prevention and treatment of pneumonia. Expert Opin Drug Saf 2009;8(4):435-449

69 Olland A, Falcoz PE, Kessler R, Massard G. Should cystic fibrosis patients infected with Burkholderia cepacia complex be listed for lung transplantation? Interact Cardiovasc Thorac Surg 2011;13(6): 631-634

70 Almuzara M, Limansky A, Ballerini V, Galanternik L, Famiglietti A, Vay C. In vitro susceptibility of Achromobacter spp. isolates: comparison of disk diffusion, Etest and agar dilution methods. Int J Antimicrob Agents 2010;35(1):68-71

71 Wang M, Ridderberg W, Hansen CR, et al. Early treatment with inhaled antibiotics postpones next occurrence of Achromobacter in cystic fibrosis. J Cyst Fibros 2013;12(6):638-643

72 Atalay S, Ece G, Samlioğlu P, Kose S, Maras G, Gonullu M. Clinical and microbiological evaluation of eight patients with isolated Achromobacter xylosoxidans. Scand J Infect Dis 2012;44(10): 798-801

73 Bador J, Amoureux L, Blanc E, Neuwirth C. Innate aminoglycoside resistance of Achromobacter xylosoxidans is due to AxyXY-OprZ, an RND-type multidrug efflux pump. Antimicrob Agents Chemother 2013;57(1):603-605

74 Yamamoto M, Nagao M, Hotta G, et al. Molecular characterization of IMP-type metallo- $\beta$-lactamases among multidrug-resistant Achromobacter xylosoxidans. J Antimicrob Chemother 2012; 67(9):2110-2113

75 Gibson RL, Burns JL, Ramsey BW. Pathophysiology and management of pulmonary infections in cystic fibrosis. Am J Respir Crit Care Med 2003;168(8):918-951

76 Ciofu O, Hansen CR, Høiby N. Respiratory bacterial infections in cystic fibrosis. Curr Opin Pulm Med 2013;19(3):251-258

77 Biswas S, Dubus JC, Reynaud-Gaubert M, Stremler N, Rolain JM. Evaluation of colistin susceptibility in multidrug-resistant clinical isolates from cystic fibrosis, France. Eur J Clin Microbiol Infect Dis 2013;32(11):1461-1464

78 Vandamme P, Dawyndt P. Classification and identification of the Burkholderia cepacia complex: Past, present and future. Syst Appl Microbiol 2011;34(2):87-95

79 Drevinek P, Mahenthiralingam E. Burkholderia. In: de Filippis I, McKee ML, eds. Molecular Typing in Bacterial Infections. New York: Humana Press; 2013:301-308

80 Abbott IJ, Slavin MA, Turnidge JD, Thursky KA, Worth LJ. Stenotrophomonas maltophilia: emerging disease patterns and challenges for treatment. Expert Rev Anti Infect Ther 2011;9(4):471-488

81 Papp-Wallace KM, Taracila MA, Gatta JA, Ohuchi N, Bonomo RA, Nukaga $M$. Insights into $\beta$-lactamases from Burkholderia species, 
two phylogenetically related yet distinct resistance determinants. J Biol Chem 2013;288(26):19090-19102

82 Pope CF, Gillespie SH, Moore JE, McHugh TD. Approaches to measure the fitness of Burkholderia cepacia complex isolates. J Med Microbiol 2010;59(Pt 6):679-686

83 Holden MT, Seth-Smith HM, Crossman LC, et al. The genome of Burkholderia cenocepacia J2315, an epidemic pathogen of cystic fibrosis patients. J Bacteriol 2009;191(1):261-277

84 Pope CF, Gillespie SH, Pratten JR, McHugh TD. Fluoroquinoloneresistant mutants of Burkholderia cepacia. Antimicrob Agents Chemother 2008;52(3):1201-1203

85 Amoureux L, Bador J, Siebor E, Taillefumier N, Fanton A, Neuwirth C. Epidemiology and resistance of Achromobacter xylosoxidans from cystic fibrosis patients in Dijon, Burgundy: First French data.J Cyst Fibros 2013;12(2):170-176

86 Bador J, Amoureux L, Duez JM, et al. First description of an RNDtype multidrug efflux pump in Achromobacter xylosoxidans, AxyABM. Antimicrob Agents Chemother 2011;55(10): 4912-4914

87 Traglia GM, Almuzara M, Merkier AK, et al. Achromobacter xylosoxidans: an emerging pathogen carrying different elements involved in horizontal genetic transfer. Curr Microbiol 2012; 65(6):673-678

88 Turton JF, Mustafa N, Shah J, Hampton CV, Pike R, Kenna DT. Identification of Achromobacter xylosoxidans by detection of the bla(OXA-114-like) gene intrinsic in this species. Diagn Microbio Infect Dis 2011;70(3):408-411

89 Glupczynski Y, Hansen W, Freney J, Yourassowsky E. In vitro susceptibility of Alcaligenes denitrificans subsp. xylosoxidans to 24 antimicrobial agents. Antimicrob Agents Chemother 1988; 32(2):276-278

90 Tsay RW, Lin LC, Chiou CS, et al. Alcaligenes xylosoxidans bacteremia: clinical features and microbiological characteristics of isolates. J Microbiol Immunol Infect 2005;38(3):194-199
91 Jacquier H, Le Monnier A, Carbonnelle E, et al; Gmc Study Group. In vitro antimicrobial activity of "last-resort" antibiotics against unusual nonfermenting Gram-negative bacilli clinical isolates. Microb Drug Resist 2012;18(4):396-401

92 Valenza G, Tappe D, Turnwald D, et al. Prevalence and antimicrobial susceptibility of microorganisms isolated from sputa of patients with cystic fibrosis. J Cyst Fibros 2008;7(2):123-127

93 Huang CH, Jang TN, Liu CY, Fung CP, Yu KW, Wong WW. Characteristics of patients with Burkholderia cepacia bacteremia. J Microbiol Immunol Infect 2001;34(3):215-219

94 Liao $\mathrm{CH}$, Chang HT, Lai CC, et al. Clinical characteristics and outcomes of patients with Burkholderia cepacia bacteremia in an intensive care unit. Diagn Microbiol Infect Dis 2011;70(2):260-266

95 Hogardt M, Schmoldt S, Götzfried M, Adler K, Heesemann J. Pitfalls of polymyxin antimicrobial susceptibility testing of Pseudomonas aeruginosa isolated from cystic fibrosis patients. J Antimicrob Chemother 2004;54(6):1057-1061

96 Rolston KV, Kontoyiannis DP, Yadegarynia D, Raad II. Nonfermentative gram-negative bacilli in cancer patients: increasing frequency of infection and antimicrobial susceptibility of clinical isolates to fluoroquinolones. Diagn Microbiol Infect Dis 2005; 51(3):215-218

97 US FDA. FDA Drug Safety Communication: FDA warns of increased risk of death with IV antibacterial Tygacil (tigecycline) and approves new Boxed Warning. 2013. Accessed August 8, 2014. Available at http://www.fda.gov/Drugs/DrugSafety/ucm369580.htm

98 Cooreman S, Jeurissen A. Comment on: Newer antibacterial agents and their potential role in cystic fibrosis pulmonary exacerbation management. J Antimicrob Chemother 2011;66(5):1197-1198, author reply 1198-1199

99 Owens B. Silver makes antibiotics thousands of times more effective. Nature News. Macmillan Publishers Ltd, 19 June 2013. Accessed August 9, 2014. Available at http://www.nature.com/news/silvermakes-antibiotics-thousands-of-times-more-effective-1.13232 